\title{
Yellow fever vaccination in egg-allergic patients
}

\author{
Gema Ruíz*1 ${ }^{* 1}$ Eugenia Sanchis-Merino², Blanca Monsalve ${ }^{3}$, Isabel Pérez ${ }^{4}$, Marta Allue ${ }^{4}$, Clara Berbel ${ }^{4}$ \\ ${ }^{1}$ Clinic University Hospital of Valladolid, Unit of Preventive Medicine and Public Health, Spain \\ ${ }^{2}$ Allergy Unit, Rio-Hortega University Hospital, Spain \\ ${ }^{3}$ Gregorio Marañón University Hospital, Madrid, Spain \\ ${ }^{4}$ Territorial Service of Health and Social Welfare, International Vaccine Centre of Valladolid, Spain
}

Received: July 1, 2015

DOI: $10.5430 /$ jer.v2n2p22
Accepted: December 15, $2015 \quad$ Online Published: December 17, 2015

URL: http://dx.doi.org/10.5430/jer.v2n2p22

\begin{abstract}
Yellow Fever Vaccine is contraindicated in egg-allergic people. However, under certain circumstances, its administration may be possible and advisable. We present two clinical cases of egg allergic children who were vaccinated against yellow fever following a short staggered administration protocol of the vaccine at a specialized hospital Unit. We explain the vaccination protocol applied in the Allergy Unit of Rio-Hortega University Hospital, Spain, with the coordination of The International Vaccination Centre.
\end{abstract}

Key Words: Allergy, Anaphylaxis, Egg allergy, Yellow fever vaccine

\section{INTRODUCTION}

Yellow Fever is an acute viral disease transmitted by infected mosquitoes Aedes aegypti or Haemagogus spp. The virus is found in tropical areas of Africa and South America where it is endemic in 43 countries. ${ }^{[1]} \mathrm{A}$ traveller risk for acquiring yellow fever is variable and determined by various factors, including immunization status, location of travel and local rate of virus transmission at the time of travel. ${ }^{[2]}$ The World Health Organization (WHO) estimates that Yellow Fever virus causes 200,000 cases of clinical disease and 30,000 deaths each year. Over the last years, International Travel Vaccination Centres are increasingly contacted by people allergic to vaccine components who decide to travel to endemic countries or countries with an increase risk of yellow fever outbreaks. Vaccination with a live-virus vaccine, used since 1937 is the most important preventive measure against yellow fever. ${ }^{[3]}$

The rate of any adverse events following Yellow Fever vaccine as reported to Vaccine Adverse Event Reporting System is 43 adverse events per 100,000 doses distributed. The majority of reported adverse events are classified as nonserious (rate: 38 per 100,000 population) and include reports of fever, injection-site pain, injection-site erythema, swelling, pruritus, headache, urticaria, and rash. The majority of events occur a median of 1 day after vaccination; roughly $60 \%$ occur within the first 2 days after vaccination. ${ }^{[4]}$ Severe allergic reaction or anaphylaxis, characterized by urticaria and respiratory symptoms (e.g., dyspnea, bronchospasm, or pharyngeal edema) occurs in $0.4-1.8$ cases $/ 100,000$ vaccines, most of them in patients with egg allergy or who are allergic to other vaccine components like gelatin. ${ }^{[3-5]}$

Egg allergy is one of the most common food allergies in children ${ }^{[7]}$ with a prevalence of $2.5 \%$ in the first two years of life. ${ }^{[8,9]}$ Most children will outgrow at five years old and it is closely associated with milk allergy and atopic dermatitis. ${ }^{[10]}$

Five major allergenic proteins from the egg have been identified: ovomucoid (Gal d 1), ovalbumin (Gal d 2), ovotransferrin (Gal d 3), lysozyme (Gal d 4) and albumin (Gal d

*Correspondence: Gema Ruíz, MD, PhD; Email: cordoba_sweet@hotmail.com; Address: Avda. Ramón y Cajal, Nº3. CP: 47005, Valladolid, Spain. 
5). Although ovalbumin is the most abundant protein comprising hen's egg white, ovomucoid has been shown to be the dominant egg allergen because it is resistant to heat and digestive enzymes. ${ }^{[11]}$ Children typically present with rapid onset of urticaria and angioedema, usually within minutes to two hours after ingestion, and occasionally generalized responses involving the gastrointestinal, cardiovascular or respiratory tracts are also reported, even after eating small quantities of fresh hen's egg. ${ }^{[12]}$

Controversy remains over vaccination in egg-allergic children. Vaccines that contain small quantities of egg protein like mumps-measles-rubella vaccines (MMRV), influenza vaccines (IVs) and yellow fever vaccine (YFV) can cause hypersensitivity reactions in some people with egg allergy. ${ }^{[13-15]}$

Even after extensive purification, final vaccine products may contain small quantities of avian proteins resembling proteins present in hens' eggs. Also many different nonmicrobial constituents of vaccines could potentially result in systemic allergic reactions (gelatin, antimicrobial agents, yeast, and natural rubber latex). ${ }^{[5,16-18]}$

Current guidelines recommend a prior consultation with an allergist. Vaccines should be administered in settings in which personnel and equipment for rapid recognition and treatment of anaphylaxis are available though vaccines with small amounts of egg proteins can be administered in Primary Care facilities. Procedures should be in place to avoid injuries from falling and to restore cerebral perfusion if syncope occurs. ${ }^{[19-21]}$

YFV is grown in chicken embryos with attenuated virus. It is not heated during manufacturing and therefore still contains egg proteins that would otherwise be destroyed by heat. The amount of residual egg protein remains unavailable to the manufacturer. ${ }^{[13]}$ YFV can also contain chicken proteins and gelatin. ${ }^{[5,22]}$ YFV administered in Spain, Stamaril ${ }^{\circledR}$ (Sanofi Pasteur MSD, S.A., Madrid), does not contain antibiotics, gelatin or any other additive agents and provides effective immunity for $95 \%$ of vaccinated people.

There are very few reports of anaphylactic reactions to YFV and these ones date from 1940s. The rate of YF vaccinerelated anaphylaxis would be 40 in 5,236,820 or about 1 in 131,000 doses distributed, according to the Vaccine Adverse Event Reporting System between 1990 and 1997. ${ }^{[5]}$ Roken et al. in a 7 patients' study found that a dose of $0.1 \mathrm{ml}$ vaccine is sufficient to induce a protective antibody response ${ }^{[23]}$ and several authors describe protocols to administer several doses of YFV in specialized Allergy Units in order to achieve correct vaccination. ${ }^{[20,24]}$
Because of the risk for serious adverse events that can occur following YF vaccine administration, health-care providers should vaccinate only persons who are at risk for exposure to YF virus or require proof of vaccination for country entry. To minimize further the risk for serious adverse events, health-care providers should observe the contraindications carefully and consider the precautions to vaccination before administration of YF vaccine and provide a medical waiver when needed. ${ }^{[19,20]}$

We present the cases of two egg-allergic children who need to be vaccinated against yellow fever to travel with their families. We explain the vaccination protocol applied in the allergy unit of Rio-Hortega University Hospital and the coordination with International Vaccination Centre of Valladolid to deal with patients with egg allergy.

\section{Case Reports}

\subsection{Case 1}

A four years and 10 months old girl who must travel with her family to Colombia, an endemic yellow fever area was previously diagnosed with egg allergy when she was one-year-old. After eating egg she presented a rapid onset of rejection of the food, peribucal urticaria and generalized micropapular eruption that resolved spontaneously after 45 minutes.

She presented positive skin prick test (PT) to white egg, yolk, ovalbumin and ovomucoid. She also presented positive specific IgE determinations to egg proeteins: egg (1.50 KU/L), yolk $(0.62 \mathrm{KU} / \mathrm{L})$ and ovalbumin $(0.59 \mathrm{KU} / \mathrm{L})$. From this episode she completely excluded egg intake in her diet. No other food allergies were detected.

\subsection{Case 2}

A 23-month-old boy needs to travel to Paraguay and Brazil to a family event. He was diagnosed with egg allergy at 12 months old. Yellow fever vaccine had been previously contraindicated.

Egg allergy was diagnosed when he presented, after eating egg, an acute onset of hives around the mouth, generalized urticaria and vomiting that stopped after symptomatic treatment at Emergency Department. He presented positive PT to egg, yolk, white egg and ovoalbumin and positive specific IgE determinations of egg ( $5 \mathrm{KU} / \mathrm{L})$, white egg (3.76 $\mathrm{KU} / \mathrm{L})$, yolk (5.21 KU/L) and ovalbumin (4.01 KU/L) and negative to ovomucoid $(<0.35 \mathrm{KU} / \mathrm{L})$. He was diagnosed with anaphylactic reaction secondary to egg sensitivity and he follows an egg-free and milk-free diet.

Both children are properly vaccinated from vaccines include in Spanish official recommendations for children vaccination including MMRV which was administered at our Hospital 
Allergy Unit in case 1 and at his health centre in case 2.

Although current protocols and YFV manufacturer's data sheet contraindicate the vaccination and thus the travel in both cases, we proposed to the families the possibility to receive YFV (Stamaril ${ }^{\circledR}$, Sanofi Sanofi Pasteur S.A, France) in a specialized unit so they were referred to the Allergy Unit of the Rio-Hortega University Hospital (Valladolid).

\section{HeAlth INTERVENTION AND RESULtS}

Parents of both patients signed a written informed consent form. Skin PT (2,000 UI/ml) and intradermal test $(20 \mathrm{UI} / \mathrm{ml})$ ) with YFV were performed. Skin PT with latex and gelatin were done. All these tests were negative.

Stamaril ${ }^{\circledR}$ was administered under strict observation at the Allergy Unit of the Rio-Hortega University Hospital following the schedule which consists of intramuscular administration doses of $0.05,0.15$ and $0.30 \mathrm{ml}$ of Stamaril ${ }^{\circledR}$ in 30 minutes intervals. ${ }^{[24]}$ Clinical staff of the International Vaccination Centre moved to the Hospital to provide YFV and subsequently certified with an official card the correct vaccination against yellow fever. Physicians and nurses were available for immediate consultation and equipment to treat allergic reactions, even anaphylaxis, and carry out cardiopulmonary resuscitation were accessible at this facility.

Both patients remained asymptomatic without any local reactions 60 minutes after the last doses were administered. No late reactions were observed.

\section{Discussion}

Every year, an increased number of people move out of our country and nowadays we can observe a crescent number of patients with pathologies or conditions that increase the risk of travelling. Some allergic patients who decide to travel to an endemic country has an increased risk of developing adverse reactions when it is necessary to vaccine them to some diseases, such as MMR, Influenza or yellow fever. For this reason, we consider that multidisciplinary protocols that can offer the best solutions and their alternatives to the allergic patients, who decide to travel to an endemic country, must be developed.

The rate of severe allergic reactions to vaccines is very low, ranging between 0.5-1/100,000 doses and generally, causes are often due to low concentrations of protein components ac-

\section{REFERENCES}

[1] WHO. Yellow Fever. 2015. Available from: http://www. who. in t/immunization/diseases/yellow_fever/en/

[2] CDC. Yellow Book Home I Travelers' Health. CDC 2014. Avail- quired during the manufacturing process, such as egg, gelatin, yeast or latex. ${ }^{[25-27]}$ In spite of this very low rate of allergic reactions, in some vaccines (MMR, IV, YF), the manufacturer's data sheet indicates the contraindication to use them in patients allergic to any of their components, so that many times they are not use in these patients.

Egg proteins concentrations are higher in embryonated chicken eggs vaccines (influenza, yellow fever, rabies) and lower in chicken embryos or fibroblasts of chicken embryos vaccines (Measles-Mumps-Rubella). Nevertheless, if the administration of some vaccines are necessary, such as YFV in certain cases, it is mandatory to inform the patients and referred them to an Allergy Unit to evaluate available alternatives: staggered dose administration or a desensitization protocol at specialized Allergy facilities since anaphylaxis after YFV has been previously described. ${ }^{[5]}$ The European Union legislation has established a $2 \mu \mathrm{g} / \mathrm{ml}$ egg proteins concentration as the maximum concentration allowed, since it is considered a safe amount in patients with previous egg's anaphylaxis. ${ }^{[28]}$ YFV contains higher amounts of egg-proteins in comparison with MMR and IVs, so that all subjects with a previous systemic reactions with egg must be submit to an Allergy Unit to be evaluated before vaccination and to be performed prick skin and intradermal test with YFV, and if it is necessary, for receiving vaccination under hospital supervision. ${ }^{[29,30]}$ Diagnosis of vaccine allergy is important not only to prevent serious or even life-threatening reactions, but also to avoid unnecessary vaccine restriction. ${ }^{[31]}$

In our egg-allergic patients, YFV was not avoided, but difficulties appeared when it was necessary to contact different Units (Allergy Unit and International Vaccination Centre) in order to deal with potential adverse reactions and certify correct vaccination. We adopted a short protocol used by Muñoz-Cano et al., which is tolerated without problems. ${ }^{\text {[24] }}$ The Cambridge Allergy 7-step protocol allows for its safe administration in patients with positive SPT to YFV. A 2-step protocol can be used in patients with negative YFV SPT.

\section{Conclusion}

Under certain circumstances, YFV administration is possible to egg allergy children. A specialized hospital unit is necessary to apply the standardized protocol in order to control the health situation. Smooth communication between different units can reduce bureaucratic delays.

able from: http://wwwnc.cdc.gov/travel/page/yellowbo ok-home-2014

[3] Lloyd W, Theiles M, Ricci NI. Modification of the virulence of yellow fever virus by cultivation in tissues in vitro. Trans $\mathrm{R}$ Soc Trop 
Med Hyg. 1936; 29(5): 481-529. http://dx.doi.org/10.1016 /S0035-9203(36) 90002-0

[4] Lindsey NP. Adverse event reports following yellow fever vaccination. Vaccine. 2008; 26: 6077-6082. PMid:18809449 http: //dx.doi.org/10.1016/j.vaccine.2008.09.009

[5] Kelso JM, Mootrey GT, Tsai T. Anaphylaxis from yellow fever vaccine. J Allergy Clin Immunol. 1999; 103: 698-701. http: //dx.doi.org/10.1016/S0091-6749(99)70245-9

[6] Rutkowski K, Ewan PW, Nasser SM. Administration of yellow fever vaccine in patients with egg allergy. Int Arch Allergy Immunol. 2013; 161(3): 274-8. PMid:23548550 http://dx . doi .org/10.1159/0 00346350

[7] Martorell A, et al. Position document: IgE-mediated allergy to egg protein. Allergol Immunopathol (Madr). 2013; 41(5): 320-36. PMid:23830306 http://dx.doi.org/10.1016/j.aller. 2013. 03.005

[8] Eggesbo M, et al. The prevalence of allergy to egg: a populationbased study in young children. Allergy. 2001; 56(5): 403-11. PMid:11350303 http://dx.doi.org/10.1034/j.1398-9995. 2001.056005403.x

[9] Tan JW, Joshi P. Egg allergy: an update. J Paediatr Child Health. 2014; 50(1): 11-5. PMid:24134462 http://dx.doi.org/10.11 $11 /$ jpc. 12408

[10] Osborne NJ, et al. Prevalence of challenge-proven IgE-mediated food allergy using population-based sampling and predetermined challenge criteria in infants. J Allergy Clin Immunol. 2011; 127(3): 668-76 e1-2.

[11] Jacobsen B, et al. The panel of egg allergens, Gal d 1-Gal d 5: Their improved purification and characterization. Mol Nutr Food Res. 2008; 52 Suppl 2: S176-85. http://dx. doi .org/10.1002/mnfr. 2007 00414

[12] Bindslev-Jensen C, Briggs D, Osterballe M. Can we determine a threshold level for allergenic foods by statistical analysis of published data in the literature? Allergy. 2002; 57(8): 741-6.13.

[13] Chung EH. Vaccine allergies. Clin Exp Vaccine Res. 2014; 3(1): p.50-7. PMid:24427763 http://dx. doi .org/10.7774/cevr. 20 14.3 .1 .50

[14] Kelso JM. Raw egg allergy-a potential issue in vaccine allergy. J Allergy Clin Immunol. 2000; 106(5): 990. PMid:11080728 http: //dx.doi.org/10.1067/mai.2000.110800

[15] Institute of Vaccine Safety. John Hopkins Bloomber School of Public Health. Allergens. 2013. Available from: http://www. vaccines af ety.edu/components-Allergens.htm

[16] Offit PA, Jew RK. Addressing parents' concerns: do vaccines contain harmful preservatives, adjuvants, additives, or residuals? Pediatrics. 2003; 112(6Pt1): 1394-7. PMid:14654615 http://dx.doi.org/1 $0.1542 /$ peds.112.6.1394

[17] Kelso JM, Jones RT, Yunginger JW. Anaphylaxis to measles, mumps, and rubella vaccine mediated by IgE to gelatin. J Allergy Clin Immunol. 1993; 91 (4): 867-72. http://dx.doi.org/10.1016/009 $1-6749(93) 90344-\mathrm{F}$
[18] Centers for Disease Control and Prevention. Epidemiology and Prevention of Vaccine-Preventable Diseases, t.E. Vaccine Excipient \& Media Summary. Excipients Included in U.S. Vaccines, by Vaccine. Appendix B. 2015. Available from: www.cdc.gov/vaccines/pub s/pinkbook/B/excipient-table-2.pdf

[19] Staples JE, et al. Yellow Fever Vaccine Booster Doses: Recommendations of the Advisory Committee on Immunization Practices. 2015. MMWR Morb Mortal Wkly Rep. 2015; 64(23): 647-50. PMid:26086636

[20] Staples JE, Gershman M, Fischer M. Yellow fever vaccine: recommendations of the Advisory Committee on Immunization Practices (ACIP). MMWR Recomm Rep. 2010; 59(RR-7): 1-27.

[21] General recommendations on immunization. Recommendations of the Advisory Committee on Immunization Practices (ACIP). MMWR Recomm Rep. 2011; 60(2): 1-64.

[22] Kelso JM, Greenhawt MJ, Li JT. Update on influenza vaccination of egg allergic patients. Ann Allergy Asthma Immunol. 2013; 111(4): 301-2. PMid:24054370 http://dx.doi.org/10.1016/j.anai . 2013.07.030

[23] Roukens AH, et al. Reduced intradermal test dose of yellow fever vaccine induces protective immunity in individuals with egg allergy Vaccine. 2009; 27(18): 2408-9. PMid:19368780 http://dx.doi.o $\mathrm{rg} / 10.1016 / \mathrm{j}$. vaccine .2009 .02 .049

[24] Munoz-Cano R, et al. Yellow fever vaccine and egg allergy: really a problem? Allergy; 2010; 65(4): 533-4. PMid:19839970 http://dx.doi.org/10.1111/j.1398-9995.2009.02205.x

[25] Zudaire LE, del Castillo LO, Lebrero EA, et al. Consensus position document on the child with an allergic reaction after vaccination or an allergy to vaccine components. An Pediatr (Barc). 2015; 83(1): 631-63e10

[26] Yavuz ST, et al. Anaphylactic reactions to measles-mumps-rubella vaccine in three children with allergies to hen's egg and cow's milk. Acta Paediatr. 2011; 100: e94-e96. PMid:21244488 http: //dx.doi.org/10.1111/j.1651-2227.2011.02165.x

[27] Rottem M, Shoenfeld Y. Vaccination and allergy. Curr Opin Otolaryngol Head Neck Surg. 2004; 12(3): 223-31. PMid:15167034 http: //dx.doi.org/10.1097/01.moo.0000122312.13359.eb

[28] Franceschini $\mathrm{F}$, et al. Vaccination in children with allergy to non active vaccine components. Clin Transl Med. 2015; 4: 3. PMid:25852819 http://dx.doi.org/10.1186/s40169-014-0 043-0

[29] Kelso JM. Allergic reactions after immunization. Ann Allergy Asthma Immunol. 2013; 110(6): 397-401. PMid:23706707 http: //dx.doi.org/10.1016/j.anai.2013.03.001

[30] Chernin LR, Swender D, Hostoffer RW. Cracking the Shell on Egg-Hypersensitive Patients and Egg-Containing Vaccine. J Am Osteopath Assoc. 2011; 111(10 suppl 6): S5-S7. PMid:22086894

[31] Caubet JC, et al. Managing a child with possible allergy to vaccine. Pediatr Allergy Immunol. 2014; 25(4): 394-403. PMid:24131271 http://dx.doi.org/10.1111/pai.12132 